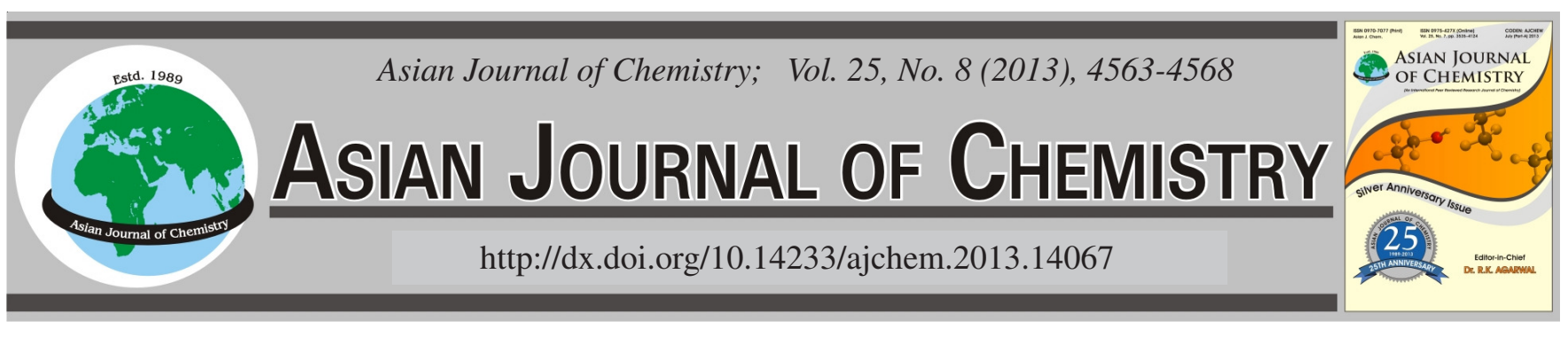

\title{
Kinetic Spectrophotometric Methods for the Determination of Isatin
}

\author{
Zeid A. Alothman ${ }^{1}$, Masoom Raza Siddiqui ${ }^{1, *}$, Saikh Mohammad Wabaidur ${ }^{1}$, \\ Hamad A. Al-Lohedan ${ }^{2}$, Mohd. SAIID Ali ${ }^{2}$ and M.Z.A. RafiQueE ${ }^{2}$
}

\begin{abstract}
${ }^{1}$ Advanced Materials Research Chair, Chemistry Department, College of Science, King Saud University, Riyadh, Saudi Arabia ${ }^{2}$ Surfactant Research Chair, Department of Chemistry, College of Science, King Saud University, Riyadh, Saudi Arabia

*Corresponding author: E-mail: siddiqui124@gmail.com
\end{abstract}

(Received: 19 May 2012;

Accepted: 15 February 2013)

AJC-13013

\begin{abstract}
Simple, rapid and sensitive kinetic spectrophotometric methods are described for the analysis of isatin in pure form and in mixture. The procedures were based on the kinetic investigations and studies were done upon the oxidation of isatin with potassium permanganate in basic medium. Various parameters affecting the colour developments were investigated and parameters were optimized. The reliability and the analytical performance of the proposed methods were validated for its linearity, range, accuracy and precision. The calibration curves were linear over the range of $5-50 \mu \mathrm{g} \mathrm{mL}^{-1}$. The limit of detection and limit of quantitation of the two methods ranges from $3.4 \times 10^{-4}-0.878$ and $1.05 \times 10^{-3}-2.663$, respectively. The possible mechanism of the reaction is also proposed.
\end{abstract}

Key Words: Isatin, Spectrophotometry, Method development, Method validation.

\section{INTRODUCTION}

Chemically, isatin is known as $1 H$-indole-2,3-dione. It was discovered by Erdman and Laurent ${ }^{1}$ and is reported to be present in the mammalian tissues and fluids and also found in various plants ${ }^{2}$. Owing to remarkable antibacterial and antifungal properties ${ }^{3}$ this compound has a great significance in medicinal chemistry. Various biological activities are associated with isatin that include analgesic, CNS activities and anticonvulsant, antidepressant, antiinflammatory, antimicrobial and also reported to be capable of crossing the bloodbrain-barrier ${ }^{4}$. Several other pharmacological importance of isatin is highlighted in the literature including the induction of arousal, reduction in duration of slow-wave sleep and increase of the seizure threshold in rats. The main purpose of the discovery of the isatin was to serve as an inhibitor of monoamine oxidase (MAO) and subsequently identified as selective inhibitor of MAO $\mathrm{B}^{5,6}$. Further study on isatin revealed the fact that it acts as an antagonist of both arterial natriuretic peptide- stimulated ${ }^{7}$ and nitric oxide-stimulated ${ }^{8}$ guanylatecyclase activity. Isatin is also considered as an endogenous marker of stress and anxiety ${ }^{9}$. In view of such an important pharmacological role of isatin, there are needs to develop a cost effective, simple and sensitive method for its quality control. There are several analytical methods reported for the quantitative analysis of isatin which include electro analytical methods ${ }^{10,11}$, high performance liquid chromato- graphic method ${ }^{12}$, hyphenated techniques such as LC-MS ${ }^{13}$ GC-MS ${ }^{14}$ have their role in estimation of isatin. Fluorimetry ${ }^{15}$ and colour reaction was also exploited for the determination of isatin ${ }^{16}$. Survey of the literature reveals that till date there is no analytical method based on kinetic spectrophotometry for the determination of isatin. There is, therefore, a need for a simple and sensitive kinetic spectrophotometric method for the determination of isatin.

Kinetic methods have been applied here for the estimation owing to certain advantages in pharmaceutical analysis, regarding selectivity and elimination of additive interferences, which affect direct spectrophotometric methods. During the method developmental process it was found that the reaction of potassium permanganate with isatin in alkaline medium resulted in green colour product and this reaction has not been used in past to estimate the drug spectrophotometrically.

This paper describes a simple and sensitive kinetic spectrophotometric method for the determination of isatin. The method involves the oxidation of drug with alkaline potassium permanganate at $25 \pm 1{ }^{\circ} \mathrm{C}$ and subsequent measurement of absorbance at $605 \mathrm{~nm}$. The initial rate and fixed time methods are adopted for its determination in synthetic mixture.

\section{EXPERIMENTAL}

Evolution 300, thermo UV-visible spectrophotometer, with matched quartz cells was used to measure the change in absorbance with time. Waters Aquity UPLC system (waters 
Manchester UK) was employed to validate mass of the oxidation product.

All reagents and chemicals used were of analytical or pharmaceutical grade and the solutions were prepared in Milli Q water. The isatin was obtained from Merck, Germany and was used without further purification. Aqueous solutions of $2.0 \times 10^{-1} \mathrm{M}$ sodium hydroxide and $1.26 \times 10^{-4} \mathrm{M}$ potassium permanganate (GR Grade, Merck Limited, Mumbai, India) were prepared in doubly distilled water. Potassium permanganate (GR Grade, Merck Limited, Mumbai, India) solution should be freshly prepared and its apparent purity be assayed by titrimetric method ${ }^{17}$.

Standard drug solution: The standard test solution of $0.05 \%$ isatin(Merck, Germany)was prepared by dissolving $50 \mathrm{mg}$ of isatin in $100 \mathrm{~mL}$ Milli Q water.

\section{Recommended procedure for the determination of isatin}

Initial-rate method: Aliquots of $1.26 \times 10^{-4} \mathrm{M}$ potassium permanganate solution $(2.5 \mathrm{~mL})$ and $2.0 \times 10^{-1} \mathrm{M} \mathrm{NaOH}(2.5$ $\mathrm{mL})$ were transferred into a series of $10 \mathrm{~mL}$ volumetric flask. An accurate volume of the working solution of isatin (0.1-1.0 $\mathrm{mL}$ ) was added and diluted up to the mark with the Milli Q water. The content of the mixtures were mixed well and transferred immediately to the spectrophotometric cell. The increase in absorbance was recorded as a function of time at $605 \mathrm{~nm}$. The initial rate of the reaction $(v)$ at different concentration was obtained from the slope of the tangent of the absorbancetime curve. The calibration curve was constructed by plotting the $\log$ of initial rate of reaction $(\log v)$ against the $\log$ of molar concentration of isatin $(\log C)$. The content of the drug was calculated either from the calibration graph or the linear regression equation.

Fixed-time method: The absorbance of each drug sample solution was measured at $605 \mathrm{~nm}$ against a reagent blank prepared similarly at a preselected fixed time of $20 \mathrm{~min}$. The calibration curve was constructed by plotting the absorbance against the final concentration of the drug. The amount of the drug was computed either from calibration curve or regression equation.

Determination procedure for isatin in synthetic mixture and application of the developed method: Synthetic mixtures have been used in the past for the determination of pharmaceutical compounds and check for the applicability of the proposed method ${ }^{18,19}$. The proposed method is aimed to estimate isatin in pure form as well in dosage form. Since, there was no drug formulation of isatin available in the local market the determination procedure was done on the synthetic mixture which was prepared by adding isatin to placebo. The mixture containing isatin was prepared with excipients commonly used in solid dosage forms and analyzed to check the applicability of the proposed method. The following excipients were used to prepare a synthetic mixture for solid dosage forms: isatin $(100 \mathrm{mg})$, lactose $(280 \mathrm{mg})$, silicon dioxide (40 $\mathrm{mg})$, corn starch $(360 \mathrm{mg})$, glucose $(100 \mathrm{mg})$ and magnesium stearate $(25 \mathrm{mg})$. In the synthetic mixture, the mass ratio of isatin to lactose, silicon dioxide, glucose and magnesium stearate was 1:2.8:0.4:3.6:1:0.25, respectively, where the content of lactose, silicon dioxide, corn starch, glucose and magnesium stearate forms the placebo. A portion of the synthetic mixture (active isatin + placebo) equivalent to $5-50 \mu \mathrm{g} / \mathrm{mL}$ of isatin was transferred to a $10 \mathrm{~mL}$ conical flask and measured according to either of the proposed methods mentioned above.

Interference studies: The possible interferences of amino acids and other oxidant were checked with the currently developed methods. It was found that oxidant such as chloramine $\mathrm{T}$ and sodium metavanadate interfere with the determination process while no interference was found from the oxidant such as potassium iodate. The effect of amino acids on the determination process was checked and it was found that amino acids such as proline, L-tryptophan interfere with the reagent in the determination process.

Evaluation of bias: The evaluation of bias has been done by point and interval hypothesis tests ${ }^{20,21}$. In the interval hypothesis test the proposed method (method 2) is acceptable when the true mean is within $\pm 2 \%$ of that of reference method (method 1). i.e.,

$$
-0.02 \mu_{1}<\left(\mu_{2}-\mu_{1}\right)<0.02 \mu_{1}
$$

the above equation can also be written as

$$
0.98<\frac{\mu_{2}}{\mu_{1}}<1.02
$$

This can be generalized to

$$
\frac{\theta_{\mathrm{L}}<\mu_{2}}{\mu_{1}<\theta_{\mathrm{U}}}
$$

where, $\theta_{\mathrm{L}}$ and $\theta_{\mathrm{U}}$ are lower and upper acceptance limits, respectively. The limits of this confidence interval can be calculated as the two roots of the following quadratic equation:

$$
\left.\theta^{2}\left(\overline{\mathrm{x}_{1}^{2}}-\mathrm{S}_{\mathrm{p}}^{2} \mathrm{t}_{\mathrm{tab}}^{2} / \mathrm{n}_{1}\right)-2 \theta \overline{\mathrm{x}_{1} \mathrm{x}_{2}}+\theta^{2} \overline{\left(\mathrm{x}_{2}^{2}\right.}-\mathrm{S}_{\mathrm{p}}^{2} \mathrm{t}_{\mathrm{tab}}^{2} / \mathrm{n}_{2}\right)=0
$$

where,

$$
\begin{aligned}
& \mathrm{a}=\overline{\mathrm{x}_{1}^{2}}-\frac{\mathrm{S}_{\mathrm{p}}^{2} \mathrm{t}_{\mathrm{tab}}^{2}}{\mathrm{n}_{1}} \\
& \mathrm{~b}=-2 \overline{\mathrm{x}_{1} \mathrm{x}_{2}} \\
& \mathrm{c}=\overline{\mathrm{x}_{2}^{2}}-\frac{\mathrm{S}_{\mathrm{p}}^{2} \mathrm{t}_{\mathrm{tab}}^{2}}{\mathrm{n}_{2}}
\end{aligned}
$$

The values of $\theta_{\mathrm{L}}$ and $\theta_{\mathrm{U}}$ of the confidence interval can be obtained as:

$$
\begin{array}{r}
\theta_{\mathrm{L}}=\frac{-b-\sqrt{\mathrm{b}^{2}-4 a c}}{2 a} \\
\theta_{U}=\frac{-b+\sqrt{b^{2}-4 a c}}{2 a}
\end{array}
$$

\section{RESULTS AND DISCUSSION}

Potassium permanganate acts as strong oxidizing agent, has been exploited in oxidimetric analytical method for determination of isatin. During the sequence of the reaction in basic medium the heptavalent manganese ion changes to the green colour (Mn VI). The absorption spectrum of isatin solution in doubly distilled water shows two absorption bands peaking at $218 \mathrm{~nm}$ and $242 \mathrm{~nm}$, while that of potassium permanganate 
solution in the alkaline medium exhibits an absorption band peaking at $530 \mathrm{~nm}$. The addition of potassium permanganate to the solution of pure drug produces a new characteristics band at $605 \mathrm{~nm}$ (Fig. 1). This band is attributed to the formation of isatinic acid, which resulted due to the oxidation of isatin in alkaline medium by potassium permanganate. The intensity of the green coloured product increases with time and therefore, a kinetic method was developed for the determination of isatin in pure form and in synthetic mixture.

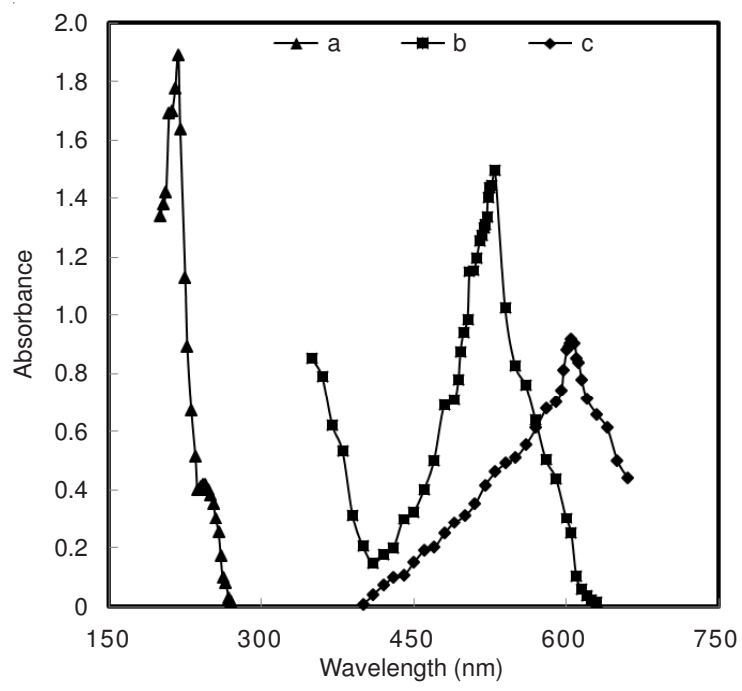

Fig. 1. Absorption spectra of (a) $3.4 \times 10^{-4} \mathrm{M}$ isatin in Milli Q water (b) $3.16 \times 10^{-4} \mathrm{M} \mathrm{KMnO}_{4}+5.0 \times 10^{-2} \mathrm{M} \mathrm{NaOH}^{+} 3.4 \times 10^{-4} \mathrm{M}$ isatin (c) $3.1610^{-4} \mathrm{M} \mathrm{KMnO}_{4}+5.0 \times 10^{-2} \mathrm{M} \mathrm{NaOH}$. The absorbance of each ((b) and (c)) was taken 20 min of mixing of the solution

Reaction mechanism: To validate the reaction product formed, reaction product was infused into the electrospray ionization-mass spectrometry (ESI-MS) in negative mode. The mass spectrum has shown that the major component is having parent mass of 164.18 (Fig. 2) which indicates the formation of isatinic $\operatorname{acid}^{22}$. On the basis of the mass spectra and the literature following mechanism could be proposed.

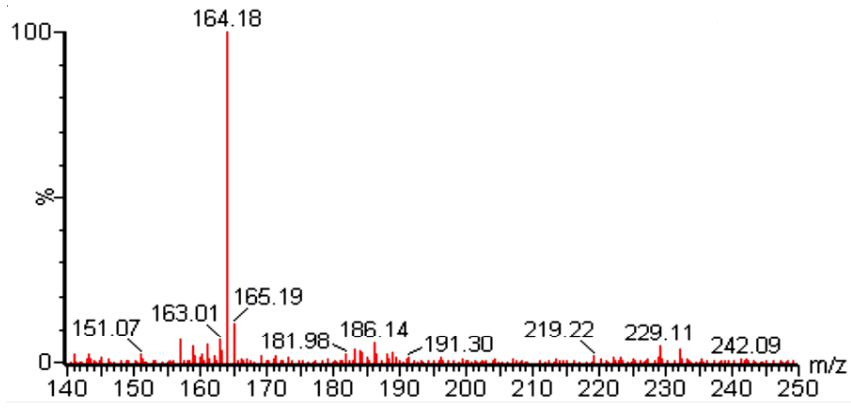

Fig. 2. Mass spectrum of the oxidized isatin in ESI-MS, using negative ionization mode<smiles>Nc1ccccc1C(=O)C(=O)O</smiles>

Optimization of variables: The influence of the concentration of $\mathrm{NaOH}$ solution on the rate of reaction was studied by keeping the constant concentrations of isatin $\left(3.40 \times 10^{-4}\right.$ $\mathrm{M})$ and $\mathrm{KMnO}_{4}\left(3.16 \times 10^{-5} \mathrm{M}\right)$ and varying the concentration of $\mathrm{NaOH}\left(2.0 \times 10^{-3}-5.0 \times 10^{-2} \mathrm{M}\right)$ in a final volume of $10 \mathrm{~mL}$ solution. Fig. 3 shows that the absorbance of reaction increased up to $4.6 \times 10^{-2} \mathrm{M} \mathrm{NaOH}$; beyond this concentration the absorbance remained constant. Therefore, a concentration of $5 \times 10^{-2} \mathrm{M} \mathrm{NaOH}$ was used throughout the experiment. In the similar way the effect of the concentration of $\mathrm{KMnO}_{4}$ solution on the change in absorbance was studied in the range of 1.27 $\times 10^{-6}-3.16 \times 10^{-5} \mathrm{M}$. The absorbance in due course of reaction (Fig. 4) increased with increasing the concentration of $\mathrm{KMnO}_{4}$ and became constant at $2.65 \times 10^{-5} \mathrm{M}$. Thus, a concentration of $3.16 \times 10^{-5} \mathrm{M} \mathrm{KMnO}_{4}$ in the final solution proved to be sufficient for the maximum concentration of isatin used in the determination process.

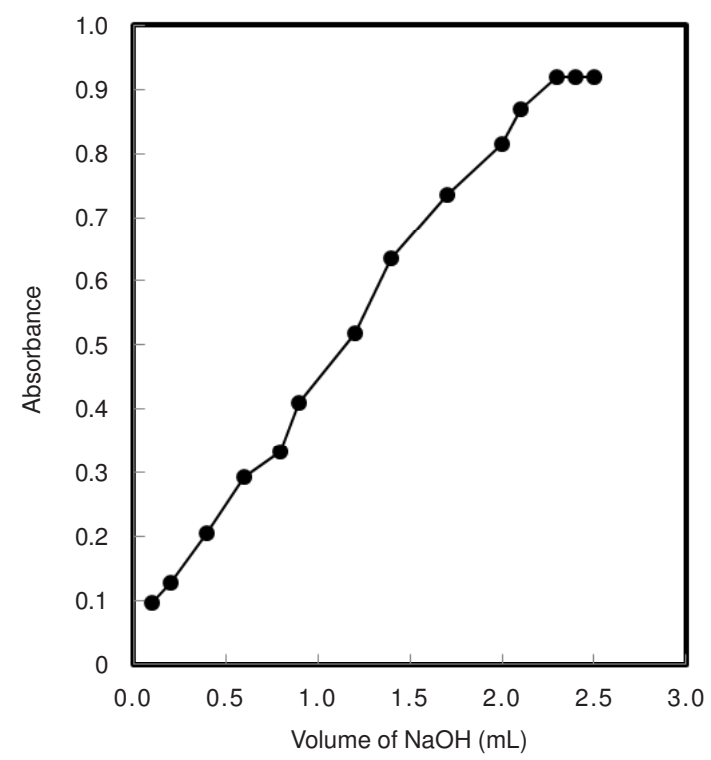

Fig. 3. Effect of volume of $\mathrm{NaOH}\left(2.0 \times 10^{-1}\right) \mathrm{M}$ keeping constant the concentration of $\mathrm{KMnO}_{4}\left(3.16 \times 10^{-4}\right)$ and isatin $\left(3.40 \times 10^{-4} \mathrm{M}\right)$

Analytical parameters and method validation: Under the optimized experimental conditions, the high difference in the concentration of potassium permanganate $\left(\mathrm{KMnO}_{4}\right)$ and sodium hydroxide solution which established a pseudo-order reaction condition with respect to the reagents concentration. Therefore, on the basis of experimental observations, kinetic equation for the reaction may be written as:

$$
\text { rate }=\mathrm{k}[\mathrm{C}]^{\mathrm{n}}\left[\mathrm{KMnO}_{4}\right]^{\mathrm{m}}[\mathrm{NaOH}]^{1}
$$

For $\left[\mathrm{KMnO}_{4}\right] \geq 1.265 \times 10^{-4} \mathrm{M}$ and $[\mathrm{NaOH}] \geq 2.0 \times 10^{-1}$ $\mathrm{M}$ at $25^{\circ} \mathrm{C}$.

The above equation reduces to:

$$
\text { rate }=\mathrm{k}_{\psi}[\mathrm{C}]^{\mathrm{n}}
$$

where $\mathrm{k}_{\psi}$ is the pseudo-order rate constant, $\mathrm{C}$ is the concentration of isatin and $\mathrm{n}$ is the order of reaction. The logarithmic form of the equation may be written as:

$$
\log (\text { rate })=\log \mathrm{k}_{\psi}+\mathrm{n} \log \mathrm{C}
$$

The initial rates of reaction were determined at different concentrations of isatin by measuring the slopes of the initial 


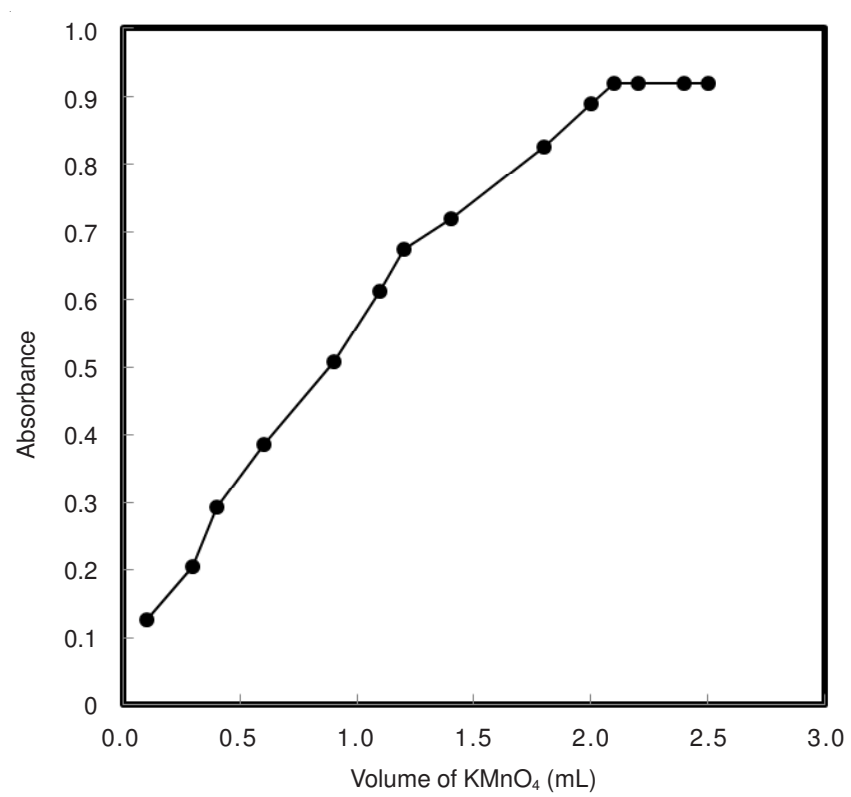

Fig. 4. Effect of volume of $\mathrm{KMnO}_{4}\left(1.26 \times 10^{-4}\right) \mathrm{M}$ keeping constant the concentration of $\mathrm{NaOH}\left(2.0 \times 10^{-1}\right)$ and isatin $\left(3.40 \times 10^{-4} \mathrm{M}\right)$

tangent to the absorbance (at $605 \mathrm{~nm}$ )-time curves during the first $20 \mathrm{~min}$ of the reaction (Fig. 5) and are summarized in Table-1. The plot of $\log$ rate versus $\log \mathrm{C}$ gave the following linear equation:

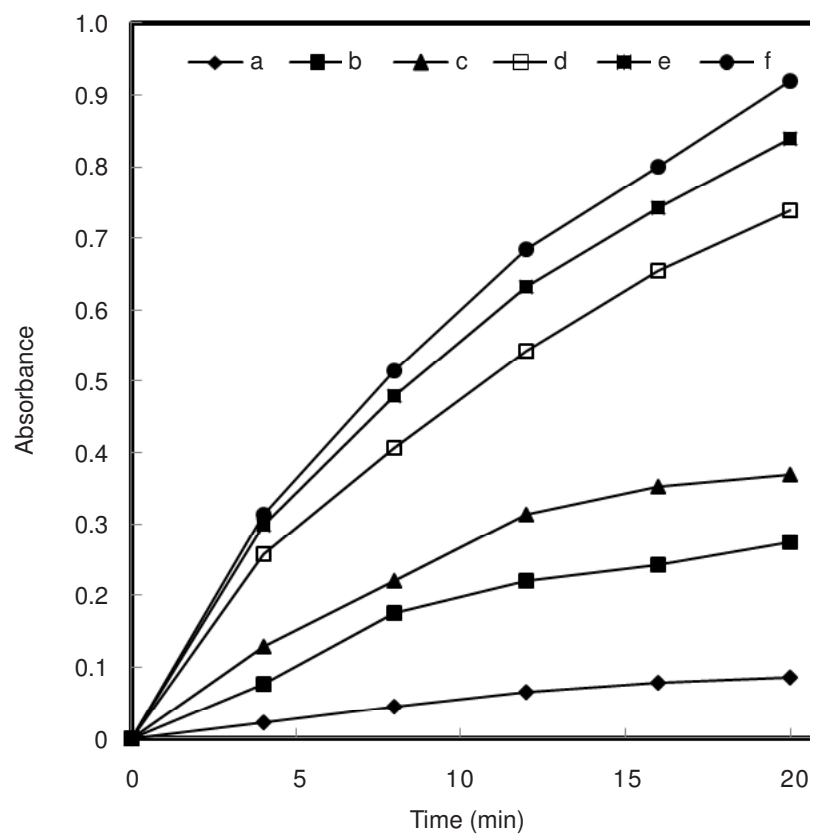

Fig. 5. Initial rate of reaction at different concentration of isatin

\begin{tabular}{cccc}
\multicolumn{4}{c}{ TABLE-1 } \\
\multicolumn{4}{c}{$\begin{array}{c}\text { INITIAL RATE OF REACTION AT DIFFERENT } \\
\text { CONCENTRATION OF ISATIN }\end{array}$} \\
\hline $\begin{array}{c}\mathrm{C} \text { [Isatin] } \\
\left(\mathrm{mol} \mathrm{L}^{-1}\right)\end{array}$ & $\log \mathrm{C}$ & $\begin{array}{c}\text { Initial rate of } \\
\text { reaction }(\mathrm{v})\end{array}$ & $\log \mathrm{v}$ \\
\hline $3.398 \times 10^{-5}$ & -4.4687 & -2.49757 & -4.4687 \\
$1.020 \times 10^{-4}$ & -3.9916 & -2.03058 & -3.9916 \\
$2.719 \times 10^{-4}$ & -3.8664 & -1.91080 & -3.8641 \\
$3.059 \times 10^{-4}$ & -3.5145 & -1.57060 & -3.5145 \\
$3.398 \times 10^{-4}$ & -3.4687 & -1.52400 & -3.4687 \\
\hline
\end{tabular}

$$
\log (\text { rate })=1.898+1.029 \log \mathrm{C}
$$

with coefficient of correlation, $r=0.9999$. The value of $n$ in the equation confirmed that the reaction is first order with respect to isatin and rate constant is $1.26 \times 10^{-2} \mathrm{~s}^{-1}$.

A calibration curve was constructed by plotting the initial rate of reaction versus initial concentration of isatin, which showed a linear response over the concentration range of 5-50 $\mu \mathrm{g} \mathrm{mL}^{-1}$. The linear regression analysis of calibration data $(n=6)$ was made to evaluate slope, intercept and correlation coefficient. The regression of rate versus concentration of isatin $\left(\mu \mathrm{g} \mathrm{mL}{ }^{-1}\right)$ gave the following linear regression equation:

$$
\text { Rate }=-4.125 \times 10^{-6}+1.151 \times 10^{-2} \mathrm{C}
$$

with a correlation coefficient ( $r$ ) of 0.9999 . The values of confidence limit for the slope $\left(\mathrm{b} \pm \mathrm{tS}_{\mathrm{b}}\right)$ and intercept $\left(\mathrm{a} \pm \mathrm{tS}_{\mathrm{a}}\right)$ of the calibration line were computed and found to be $1.151 \times$ $10^{-2} \pm 5.007 \times 10^{-5}$ and $-4.125 \times 10^{-6} \pm 1.009 \times 10^{-6}$, respectively for $\mathrm{n}-2$ degrees of freedom at $95 \%$ confidence level. The values of the confidence limit are appreciably low thus indicating the high reproducibility of the initial rate method. The limits of detection (LOD) and quantitation (LOQ) were evaluated using the following equation:

$$
\mathrm{LOD}=3.3 \times \frac{\mathrm{S}_{0}}{\mathrm{~b}} \text { and } \mathrm{LOQ}=10 \times \frac{\mathrm{S}_{0}}{\mathrm{~b}}
$$

where $\mathrm{S}_{0}$ is the standard deviation of the calibration line and $\mathrm{b}$ is the slope and found to be $3.4 \times 10^{-4}$ and $1.05 \times 10^{-3} \mu \mathrm{g} \mathrm{mL}$ ${ }^{1}$, respectively. The variance was calculated using the equation:

$$
\mathrm{S}_{0}{ }^{2}=\frac{\sum\left(\log \mathrm{v}_{\text {expt. }}-\log \mathrm{v}_{\text {reg. }}\right)^{2}}{\mathrm{n}-2}
$$

and found to be $1.46 \times 10^{-12} \mu \mathrm{g} \mathrm{mL}^{-1}$. The low value of variance indicated negligible scattering of the experimental data points around the line of regression. The results are summarized in Table-2.

\begin{tabular}{lcc}
\multicolumn{3}{c}{ TABLE-2 } \\
\multicolumn{3}{c}{ OPTICAL CHARACTERISTICS AND ANALYTICAL DATA } \\
\multicolumn{2}{c}{ FOR THE INITIAL RATE AND FIXED TIME METHODSFOR } \\
\multicolumn{2}{c}{ THE DETERMINATION OF ISATIN } \\
\cline { 2 - 3 } \multicolumn{2}{c}{ Parameters } & \multicolumn{2}{c}{ Values } \\
\cline { 2 - 3 } \multicolumn{1}{c}{$8 \mathrm{~min}$} & Fixed time \\
\hline Time & $5-50 \mu \mathrm{g} \mathrm{mL} \mathrm{m}^{-1}$ & $5-50 \mu \mathrm{mg} \mathrm{m}^{-1}$ \\
Linear dynamic range & $-4.125 \times 10^{-6}+$ & $5.028 \times 10^{-3}+$ \\
Regression equation & $0.0115 \times \mathrm{C}$ & $0.0186 \times \mathrm{C}$ \\
& 0.9998 & 0.9999 \\
Correlation coefficient & $1.01 \times 10^{-6}$ & $4.08 \times 10^{-3}$ \\
$\mathrm{~S}_{\mathrm{a}}$ & $5.01 \times 10^{-5}$ & $1.21 \times 10^{-4}$ \\
$\mathrm{~S}_{\mathrm{b}}$ & $1.46 \times 10^{-12}$ & $2.46 \times 10^{-5}$ \\
Variance & $3.4 \times 10^{-4}$ & 0.878 \\
Limit of detection & $1.05 \times 10^{-3}$ & 2.663 \\
Limit of quantitation & & \\
\hline
\end{tabular}

Solution stability: The solution stability of isatin was checked by observing UV spectra of isatin for 5 days. The aqueous solution of the drug having two $\lambda_{\max }$ : 218 and 242 $\mathrm{nm}$, showing no change in the absorption spectra of standard and sample solutions of drug for at least 5 days, when the solutions were stored at room temperature. To check the stability of the isatin solution thin layer chromatography was 
also performed. The standard solution, sample solution of isatin was applied on TLC plates coated with silica gel and developed in chloroform-methanol $(9.0: 1.5 \mathrm{v} / \mathrm{v})$ solvent system. The plates were air-dried and spots were detected in the iodine chamber. A single spot was observed up to 5 days with $\mathrm{R}_{\mathrm{f}}=$ 0.83 corresponding to isatin proving the stability of solution up to 5 days.

Accuracy and precision: The accuracy and precision of the proposed methods were established by measuring the content of isatin in pure form at three different concentration levels (low, medium and high). The short-term (intra-day assay) and the daily precisions (inter-day assay) were performed by measuring five independent analyses at 5, 40 and $50 \mu \mathrm{g} \mathrm{mL}^{-1}$ concentration levels within one day and on five consecutive days, respectively (Table-3). The standard deviation, relative standard deviation and mean percent recoveries obtained by both the initial rate and fixed time methods can be considered to be very satisfactory.

The validity of the proposed methods was also checked by performing recovery experiments through standard addition method. For this, a known amount of the pure drug was added to synthetic mixture and then the total amount of isatin was determined following the recommended procedures and reference method. The results are summarized in Table-4, which showed recoveries in the range of 99.96-100.87\%, 100.03$100.18 \%$ for initial rate and fixed time methods, respectively. No interference from the common excipients was observed.

Robustness: The conditions are robust for the application of the proposed methods to determine the active drug in pharmaceutical formulations. Each operational parameter was checked for the robustness of the methods. The operational parameters investigated were: volume of $1.26 \times 10^{-4} \mathrm{M} \mathrm{KMnO}_{4}$ $( \pm 0.2 \mathrm{~mL})$, volume of $2.0 \times 10^{-1} \mathrm{M} \mathrm{NaOH}( \pm 0.2 \mathrm{~mL})$.

Under these conditions a synthetic mixture solution containing $6.0 \mu \mathrm{g} \mathrm{mL}^{-1}$ synthetic mixture of isatin was assayed five times by the initial rate and fixed time methods. The values of mean recovery, standard deviation and relative standard deviation represent good reliability of the proposed methods.

Applicability of the proposed methods: The proposed methods were successfully applied to the determination of isatin in synthetic mixtures prepared by adding active drug to placebo. The results of the methods proposed were compared with those of the reference method ${ }^{16}$ using point and interval hypothesis tests and are summarized in Table-5. The calculated t- (paired) and F-values at $95 \%$ confidence level do not exceed the theoretical ones ${ }^{20}$ which indicates that there are no significant differences between the performance of the proposed methods and the reference method. A bias of $\pm 2 \%$, which is based on recovery experiments, is permissible by the Canadian Health Protection Branch ${ }^{21}$. Therefore, the acceptable limit lies within $\theta_{\mathrm{L}}=0.98$ and $\theta_{\mathrm{U}}=1.02$. It is evident from Table- 5 that the true bias of all samples of drug is smaller than $\pm 2 \%$ thus, confirming that the proposed methods are reliable with acceptable recovery.

\section{Conclusion}

Initial rate and fixed time methods are applied for the routine quality control analysis of isatin in pharmaceutical formulations. The determination of isatin in the literature shows that the estimation procedures need more pretreatment/separation procedure when relying on higher instrumentation methods. Conventional extractive spectrophotometric procedures

TABLE-3

EVALUATION OF ACCURACY AND PRECISION FOR THE PROPOSED METHODS BY INTRA-DAY AND INTER-DAY ASSAY

\begin{tabular}{|c|c|c|c|c|c|}
\hline \multirow{2}{*}{ Proposed methods } & \multicolumn{2}{|c|}{ Amount $\left(\mu \mathrm{g} \mathrm{mL}^{-1}\right)$} & \multirow{2}{*}{ RSD (\%) } & \multirow{2}{*}{$\mathrm{SAE}^{\mathrm{b}}$} & \multirow{2}{*}{$\mathrm{CL}^{\mathrm{c}}$} \\
\hline & Taken & Found $\pm \mathrm{SD}^{\mathrm{a}}$ & & & \\
\hline \multicolumn{6}{|c|}{ Initial rate } \\
\hline \multirow{3}{*}{ Intra-day assay } & 5 & $5.01 \pm 0.09$ & 1.69 & 0.04 & 0.11 \\
\hline & 40 & $40.03 \pm 0.13$ & 0.32 & 0.06 & 0.16 \\
\hline & 50 & $49.76 \pm 0.34$ & 0.68 & 0.15 & 0.42 \\
\hline \multirow{3}{*}{ Inter-day assay } & 5 & $4.98 \pm 0.09$ & 1.80 & 0.04 & 0.11 \\
\hline & 40 & $40.07 \pm 0.17$ & 0.42 & 0.08 & 0.21 \\
\hline & 50 & $49.94 \pm 0.41$ & 0.82 & 0.18 & 0.51 \\
\hline \multicolumn{6}{|c|}{ Fixed time } \\
\hline \multirow{3}{*}{ Intra-day assay } & 5 & $5.00 \pm 0.06$ & 1.18 & 0.03 & 0.17 \\
\hline & 40 & $40.05 \pm 0.04$ & 0.11 & 0.02 & 0.06 \\
\hline & 50 & $50.13 \pm 0.26$ & 0.52 & 0.12 & 0.32 \\
\hline \multirow{3}{*}{ Inter-day assay } & 5 & $5.02 \pm 0.07$ & 1.39 & 0.03 & 0.09 \\
\hline & 40 & $40.04 \pm 0.07$ & 0.16 & 0.03 & 0.08 \\
\hline & 50 & $50.04 \pm 0.33$ & 0.66 & 0.15 & 0.41 \\
\hline
\end{tabular}

TABLE-4

STANDARD ADDITION METHOD FOR THE DETERMINATION OF ISATIN IN SYNTHETIC MIXTURE

\begin{tabular}{|c|c|c|c|c|c|c|}
\hline \multirow{2}{*}{$\begin{array}{l}\text { Proposed methods for } \\
\text { determination of isatin }\end{array}$} & \multicolumn{3}{|c|}{ Amount of isatin $\left(\mu \mathrm{g} \mathrm{mL}^{-1}\right)$} & \multirow{2}{*}{ Recovery (\%) } & \multirow{2}{*}{$\operatorname{RSD}(\%)$} & \multirow{2}{*}{ SAE } \\
\hline & Taken & Added & Found $\pm \mathrm{SD}^{\mathrm{a}}$ & & & \\
\hline \multirow{3}{*}{ Initial rate method } & 10 & 5 & $15.13 \pm 0.11$ & 100.87 & 0.74 & 0.05 \\
\hline & 10 & 20 & $29.99 \pm 0.42$ & 99.96 & 1.40 & 0.18 \\
\hline & 10 & 40 & $49.87 \pm 0.31$ & 99.73 & 0.62 & 0.14 \\
\hline \multirow[b]{2}{*}{ Fixed time method } & 10 & 5 & $15.02 \pm 0.22$ & 100.16 & 1.14 & 0.10 \\
\hline & 10 & 20 & $30.01 \pm 0.35$ & 100.03 & 1.15 & 0.16 \\
\hline
\end{tabular}


TABLE-5

POINT AND INTERVAL HYPOTHESIS TEST: EVALUATION OF APPLICABILITY OF THE PROPOSED METHOD AND OBSERVATION OF RESULTS OF CURRENT METHOD WITH THE EXISTING METHOD ${ }^{16}$

\begin{tabular}{|c|c|c|c|c|c|c|c|c|}
\hline \multirow{2}{*}{ Methods } & \multirow{2}{*}{$\begin{array}{c}\text { Recovery } \\
(\%)\end{array}$} & \multirow{2}{*}{ RSD } & \multirow{2}{*}{$\theta_{\mathrm{L}}$} & \multirow{2}{*}{$\theta_{\mathrm{U}}$} & \multirow{2}{*}{$\mathrm{t}$} & \multirow{2}{*}{$\mathrm{F}$} & \multicolumn{2}{|c|}{ Reference method } \\
\hline & & & & & & & Recovery & RSD \\
\hline Initial rate & 100.14 & 1.65 & 0.999 & 1.008 & 1.58 & 0.17 & 99.74 & 1.80 \\
\hline Fixed time & 100.41 & 1.44 & 0.997 & 1.004 & 0.70 & 0.19 & 100.28 & 1.75 \\
\hline
\end{tabular}

for determination of isatin are effective but are tedious, timeconsuming and require a large amount of sample and reagents and sometimes vulnerable to contamination and losses of analyte. Therefore, the current methods could be a better alternate for the determination of isatin in pure form as well as in mixtures (active drug + placebo) as these methods are simple and sensitive and do not require any laborious cleanup procedure prior to analysis and therefore, can be frequently used in the laboratories of research, hospitals and pharmaceutical industries.

\section{ACKNOWLEDGEMENTS}

The authors (Z.A.O, M.R.S, S.M.W) extended their appreciation to the Deanship of Scientific Research at King Saud University for funding the work through the research group project No. RGP-VPP-043.

\section{REFERENCES}

1. P. Zou and H.L. Koh, Rapid Commun. Mass Spectrom., 21, 1239 (2007).

2. Silva J.F.M. Da, S.J. Garden and A.C. Pinto, J. Braz. Chem. Soc., 12, 273 (2001).

3. N. Hamaue, N. Yamazaki, M. Minami, M. Endo, M. Hirahuji, Y. Monma and H. Togashi, Gen. Pharmacol., 30, 387 (1998).

4. B. Bhrigu, D. Pathak, N. Siddiqui, M.S. Alam and W. Ahsan, Int. J. Pharm. Sci. Drug Res., 2, 229 (2010)

5. V. Glover, S.K. Bhattacharya, A. Chakrabarti and M. Sandler, Stress Med., 14, 225 (1998).

6. V. Glover, M. Reveley and M. Sandler, Biochem. Pharmacol., 29, 467 (1980).
7. A.E. Medvedev, A. Clow, M. Sandler and V. Glover, Biochem. Pharmacol., 52, 385 (1996)

8. A. Medvedev, O. Bussygyna, N. Pyatakova, V. Glover and I. Severina, Biochem. Pharmacol., 63, 763 (2002).

9. S.K. Battacharya, A. Clow, A. Prareski, J. Halket,V. Glover and M. Sandler, Neurosci. Lett., 132, 44 (1991).

10. H. Xu, D. Wang, W. Zhang, W. Zhu, K. Yamamoto and L. Jin, Anal. Chim. Acta, 577, 207 (2006).

11. V.C. Diculescu, S. Kumbhat and A.M. Oliveira-Brett, Anal. Chim. Acta, 575, 190 (2006).

12. V. Manabe,Q. Gao, J. Yuan, T. Takahashi and A. Ueki, J. Chromatogr. B: Biomed. Sci. Appl., 691, 197 (1997).

13. M. Unger, W. Jacobsen, U. Holzgrabe and L.Z. Benet, J. Chromatogr. B, 767, 245 (2002).

14. J.M. Halket, P.J. Watkins, A. Przyborowska, B.L. Goodwin, A. Clow, V. Glover and M. Sandler, J. Chromatogr. B: Biomed. Appl., 562, 279 (1991).

15. K.-I. Mawatari, M. Segawa, R. Masatsuka, Y. Hanawa, F. Iinuma and M. Watanabe, Analyst, 126, 33 (2001).

16. Z. Xiang-Hui, X. Wei and L. Jun, J. Shanxi Normal Univ., [DOI]: CNKI:SUN:SFDX.0.2008-02-018.http://en.cnki.com.cn/Article_en/ CJFDTOTAL-SFDX200802018.htm.

17. Vogel's Textbook of Quantitative Chemical Analysis, Pearson Education, Singapore, edn. 6, p. 420 (2002).

18. S. Riahi, F. Hadiloo, S.M.R. Milani, N. Davarkhah, M.R. Ganjali, P. Norouzi and P. Seyfi, Drug Testing Anal., 3, 319 (2011).

19. N. Rahman, M.R. Siddiqui and S.N.H. Azmi, J. Chin. Chem. Soc., 53, 735 (2006).

20. C. Hartmann, J. Smeyers-Verbeke, W. Penninck, Y.V. Hayden, P. Venkeerberghen and D.L. Masart, Anal. Chem., 67, 4491 (1995).

21. Canada Health Protection Branch, Drug Directorate Guidelines, Acceptable Methods, Ministry of National Health and Welfare Draft (1992).

22. A.M. Ismail and A.A. Zaghloul, Int. J. Chem. Kinet., 30, 463 (1998). 